\title{
УДК 311
}

\section{БЛАГОТВОРИТЕЛЬНЫЕ ОРГАНИЗАЦИИ КАК СУБЬЕКТ СОЦИАЛЬНОЙ ПОДДЕРЖКИ}

\author{
Арефьева Анастасия Дмитриевна \\ Студент
}

Дирфилд академия

Аннотация: B рамках статьи рассмотрены вопросы участия благотворительных организаций в системе социальной поддержки населения. На примере благотворительного фонда осуществлен анализ основных направлений социальной поддержки пожилых людей и инвалидов. Проведено социологическое исследование социального самочувствия подопечных благотворительного фонда, рассмотрены основные проблемы пожилых людей и инвалидов. В рамках статьи определена положительная роль благотворительных организаций в деле социальной поддержки уязвимых групп российского населения в условиях кризисного социально-экономического состояния общества. Отмечается слабая информированность пожилых людей и инвалидов о деятельности некоммерческих организаций по социальной поддержке населения и доминирование роли государства как субъекта социальной поддержки в сознании респондентов. Определяются возможные перспективы дальнейшей деятельности благотворительных организаций в данной сфере.

Ключевые слова: социальная поддержка, благотворительные организации, пожилые люди, инвалиды, анкетирование.

\section{CHARITABLE ORGANIZATIONS AS A SUBJECT OF SOCIAL SUPPORT}

\section{Arefyeva Anastasia Dmitrievna}

\begin{abstract}
The article considers the issues of participation of charitable organizations in the system of social support of the population. Using the example of a charitable foundation, the analysis of the main directions of social support for the elderly and disabled people was carried out. A sociological study of the social wellbeing of the wards of the charitable foundation was conducted, the main problems of the elderly and disabled people were considered. The article defines the positive role
\end{abstract}


of charitable organizations in the social support of vulnerable groups of the Russian population in the conditions of a critical socio-economic state of society. There is a weak awareness of the elderly and disabled people about the activities of non-profit organizations for social support of the population and the dominance of the role of the state as a subject of social support in the minds of respondents. The possible prospects for the further activities of charitable organizations in this area are determined.

Key words: social support, charitable organizations, elderly people, disabled people, survey.

Текущая социально-экономическая ситуация в Российской Федерации остается достаточно непростой. Сохраняются признаки кризисного состояния в экономике, вызванного коронавирусной пандемией, снижается социальноэкономическое благополучие российских домохозяйств и рядовых граждан. В подобной ситуации актуализируются вопросы оказания социальной поддержки и помощи населению, требующие особого внимания со стороны научного сообщества, как в теоретическом, так и в практическом отношении. Особенности социального развития российского общества и дальнейшая эволюция институтов гражданского общества приводят к появлению новых форм социальной поддержки населения, в функционировании которых особую роль играет не только государство, но и некоммерческие организации. Среди последних следует отметить систему благотворительных организаций, роль которых в деле социальной поддержки населения будет только возрастать в ближайшем будущем.

Социальная поддержка населения являются значимым компонентом обеспечения благополучия российского населения. В социологическом контексте категория «поддержки» подразумевает активный деятельностный компонент, направленный на оказание помощи и содействия людям, оказавшимся в тяжелой жизненной ситуации. В целом под социальной поддержкой традиционно понимается система деятельности субъектов социально-ориентированной работы, направленная на решение проблем граждан, находящихся в сложных жизненных обстоятельствах [4, с. 36]. Для чего указанной группе граждан оказывается широкий перечень видов социальной поддержки от материальной и психологической до юридической помощи.

Как общественный институт социальная поддержка населения подразумевает деятельность организаций социальной сферы по 
удовлетворению социально значимых потребностей наименее защищенных слоев российского общества. Вовлечение в круг субъектов социальной поддержки благотворительных организаций является относительно новым явлением, сопутствующим в своем развитии различным направлениям филантропической деятельности в современной России. Последовательный процесс институционализации благотворительной деятельности в России (в его движении от точечного вспомоществования частных филантропов к консолидации ресурсов в рамках предусмотренных законодательством организационно-правовых форм) предполагает возрастание роли конкретных благотворительных организаций [1, с. 140].

Социальная поддержка слабозащищенных групп российского населения предполагает обращение ориентированность работы благотворительных организаций на отдельные категории граждан, к которым относятся, в частности, пожилые люди. Пожилые люди наиболее чувствительны к кризисным явлениям в социально-экономической сфере, a социальное самочувствие пожилого человека подчас напрямую зависит от уровня и качества развития системы социальной поддержки населения. Среди проблем, волнующих пожилых людей и инвалидов, по данным социологических исследований, традиционно первостепенное значение имеют: инфляция цен на товары первой необходимости (78\%), общее материальное положение (37.6\%), низкое качество медицинского обслуживания (26.4\%), а также проблема одиночества и социальной незащищенности (16.4\%) [3, с. 24].

Объектом настоящей статьи является Благотворительный Фонд помощи пожилым людям и инвалидам «Горящее сердце» (далее - Фонд), зарегистрированной в качестве юридического лица 15 июля 2020 года в г. Москве. История возникновения Фонда и дальнейшее развитие его деятельности органично связаны с возникновением у пожилых людей целого комплекса проблем социально-экономического характера в период распространения коронавирусной инфекции в 2020 г. В настоящее время генеральным направлением деятельности Фонда является содействие повышению социального благополучия и самочувствия пожилых людей и инвалидов. Поскольку уровень и качество жизни пожилого человека и инвалида складывается из целого комплекса параметров, в деятельности Фонда присутствует несколько направлений работы по социальной поддержке. Социальная поддержка, оказываемая Фондом в данном направлении, сосредоточена на одиноких пожилых людях и инвалидах, а также пожилых людях и инвалидах, проживающих в домах престарелых и интернатах. В 
рамках оказания им социальной помощи Фондом организуется работы по обеспечению пожилых людей и инвалидов продуктами питания и средствами личной гигиены. Данное направление деятельности Фонда особенно актуально в условиях запретов, введенных в период коронавирусной пандемии, когда свобода перемещения пожилых людей за пределами собственного жилья существенно ограничена.

Сотрудниками Фонда оказывается социально-психологическая поддержка пожилым людям и инвалидам. В рамках удовлетворения потребностей пожилых людей и инвалидов в соответствующем медицинском обеспечении Фондом осуществляется сбор средств на оплату лечения и реабилитации. Кроме того Фондом приобретаются и распространяются среди пожилых людей тонометры и другим медицинские приборы. Также ресурсы Фонда привлекаются для содействия проведению ремонта жилых помещений для пожилых людей и инвалидов, а также объектов социального обслуживания.

Организация совместной работы Фонда с учреждениями социального обслуживания и домами-интернатами предполагает сбор подарков пожилым людям и инвалидам к праздникам, оказание содействия по доставке товаров и медикаментов. Немаловажная часть работы Фонда ориентирована на поддержание постоянного социального контакта с пожилыми людьми и инвалидами, традиционно испытывающими дефицит личного общения и внимания к себе. Оказание социально-психологической помощи со стороны сотрудников Фонда контролируется координаторами, что позволяет достичь высокого профессионального уровня в данном вопросе. Таким образом, благотворительная деятельность Фонда в рамках оказания социальной поддержки пожилым людям и инвалидам отличается широтой осуществляемой работы и высокой социальной значимостью.

В рамках изучения деятельности Фонда как благотворительной организации, осуществляющей деятельности по социальной поддержке пожилых людей и инвалидов, был произведен социологический анализ основных проектов Фонда. В настоящий момент Фонда осуществляет реализацию пяти проектов: «Коробочка Горящего сердца», «Перепеска с одинокими людьми», «Поздравления открыткой», «Телефонное волонтерство» и «Видео-волонтерство». Первый из обозначенных проектов представляет собой организацию снабжения пожилых людей и инвалидов необходимыми им предметами быта, продуктами и подарками. В рамках проекта осуществляет мониторинг социальных потребностей пожилых людей и инвалидов, на 
основании которого осуществляется адресная помощь подопечным Фонда. В настоящий момент реализация проекта охватывает 3.000 человек.

Проект «Переписка с одинокими людьми» ориентирован на оказание социально-психологической помощи и поддержки пожилым людям и инвалидам. В рамках проекта волонтеры Фонда осуществляют восполнение дефицита внимания к пожилым людям и фактически формируются для многих из них связь с внешним миром. Данное направление работы является важной составляющей социально-психологического сопровождения, в рамках которого волонтеры (помимо личного участия) налаживают связь между самими пожилыми людьми и инвалидами. На текущий момент проект охватывает 753 человека.

В тесной связи с предыдущим проектом находится и проект «Поздравление открыткой». Его отличие заключается в возможности привлечения к проекту сторонних людей, желающих поздравить пожилых людей и инвалидов с приближающимся праздником с учетом предусмотренных психологических особенностей. Под контролем координаторов Фонда пожилым людям и инвалидам отправляется открытка или письмо, содержащие поздравления от лиц, обративших в сам Фонд. Данное направление работы Фонда отличается известного рода нестабильностью в количестве отправляемых поздравлений, но в прошедшем 2020 г. было отправлено 2156 поздравлений.

Два последних проекта («Телефонное волонтерство» и «Видеоволонтерство») близки по характеру оказываемой работы в рамках социальной поддержки пожилых людей и инвалидов. Данное направление работы осуществляется исключительно самими волонтерами Фонда, хотя в связи с растущим запросом на этот вид социально-психологической помощи и поддержки наблюдается дефицит волонтеров. На регулярной основе (это является обязательным условием) осуществляется связь примерно с 200 человек.

Исходя из вышеизложенного, можно проследить устойчивую тенденцию возрастания рабочей нагрузки на каждого отдельного волонтера Фонда. На текущий момент в штате Фонда осуществляют свою работу 45 волонтеров. Положительные отзывы со стороны обслуживаемых пожилых людей и инвалидов свидетельствуют о высокой эффективности социальной поддержки, осуществляемой Фондом. Очевидно, что в настоящее время перед Фондом стоит стратегическая задача расширения штата и развитие конструктивного взаимодействия с органами государственной власти и местного 
самоуправления. Интеграция благотворительных организаций в систему государственного социального обслуживания представляется весьма перспективными направлением развития социальной поддержки населения.

В рамках анализа социального самочувствия подопечных Фонда было осуществлено социологическое исследование по вопросам качества жизни пожилых людей и инвалидов. Для реализации задач исследования был применен метод анкетирования, в рамках которого было опрошено 75 человек. Полученные в результате анкетирования результаты свидетельствуют о значительном снижении уровня социального самочувствия пропорционально возрасту респондентов. Так, положительно оценивают свое материальное и эмоциональное положение только 22\% опрошенных в возрасте 55-60 лет и только 5\% в возрасте старше 70 лет. состояние здоровья является, наряду с материальным обеспечением, важнейшим индикатором социального самочувствия. Крайне негативные оценки собственного здоровья дали около $60 \%$ опрошенных, причем около $30 \%$ из их числа оценивают свое состояние как более болезненное по сравнению с окружающими.

Нельзя однозначно трактовать негативную оценку состояния здоровья как исключительно проблему качества медицинской помощи. По мере увеличения возраста рост числа хронических заболеваний становится неизбежным обстоятельством, хотя частота посещения врача также может оказывать позитивное воздействие на самочувствие пожилых людей и инвалидов, как в отношении медицинского обслуживания самого по себе, так и в отношении внимания к проблемам пациентов со стороны профессиональных врачей [2, с. $12]$.

Плохое состояние здоровья сокращает мобильность пожилых людей и инвалидов, препятствует их полноценной вовлеченности в социальную жизнь, разрушает социальные связи и приводит к десоциализации личности. Около $70 \%$ опрошенных лиц констатируют дефицит внимания к себе, отсутствие полноценного общения и возрастающее чувство одиночества, Подобные показатели могут провоцировать развитие подавленного и депрессивного состояний, что также приводит к проблемам со здоровьем. В данном аспекте деятельность Фонда по преодолению социальной изолированности пожилых людей и инвалидов в динамике позволяет существенно улучшить ситуацию. Более 90\% респондентов отметили положительное влияние деятельности волонтеров Фонда для преодоления чувства одиночества. Высокие оценки получает деятельность Фонда в сфере содействия оказанию медицинской помощи (83\%) и улучшению материального положения (78\%). 
Интерес представляют результаты анкетирования в части, касающейся субъектов социальной поддержки пожилых людей и инвалидов. Так, 70\% опрошенных лиц отметили ключевую роль государства в решении проблем пожилых людей и инвалидов, еще $30 \%$ видит субъектом заботы о себе своих родственников. Эти показатели свидетельствуют о слабой информированности пожилых людей и инвалидов относительно деятельности благотворительных организаций и фондов. Игнорирование возможностей частных некоммерческих структур в данной сфере является существенных препятствием на пути повышения социального благополучия и самочувствия пожилых людей и инвалидов.

Проанализированные данные позволяют в целом очертить круг проблем, снижающих общее социальное самочувствие пожилых людей и инвалидов. Эти проблемы достаточно типичны и воспроизводятся в многочисленных социологических исследованиях по данной тематике. Пожилых людей волную вопросы своего материального положения, качества медицинского обслуживания, социальной изолированности и эксклюзии. Возрастающее значение некоммерческих организаций в решении проблем социальной поддержки население положительно отмечается пожилыми людьми и инвалидами, на собственном опыте знакомых с работой благотворительных организаций. Однако в целом информированность о работе частных структур в сфере социальной поддержки населения остается достаточно низкой. Пожилые люди традиционно видит в числе субъектов заботы о себе государство и ближайших родственников.

Таким образом, в связи с полученными результатами социологического исследования можно констатировать возрастающее значение роли благотворительных организаций в деле социальной поддержки населения. Происходит качественное развитие каналов взаимодействия благотворительных организаций со слабозащищенными слоями населению, развивают основные формы и направления благотворительной деятельности по качественному повышению уровня социального самочувствия людей, находящихся в трудной жизненной ситуации. Приоритетным направлением дальнейшего развития деятельности благотворительных организаций в качестве субъекта социальной поддержки населения является последовательная интеграция и взаимодействие с системой государственного социального обслуживания. 


\section{Список литературы}

1. Горский А.А. Частная благотворительность и деятельность благотворительных организаций: некоторые результаты опросов населения // Труд и социальные отношения. 2020. № 4. С. 138-149.

2. Мороз Е. В. Стратегии включения уязвимых групп населения в общество на примере пожилых людей и инвалидов трудоспособного возраста // Социология и право. 2018. № 4 (42). С. 6-16.

3. Пожилые россияне: социальное самочувствие и образ жизни. Аналитический обзор ВЦИОМ (2019-2020). М.: Издательство ВЦИОМ, 2021. $125 \mathrm{c}$.

4. Токарева Е.А. Вопросы терминологии в праве социального обеспечения. Монография. Екатеринбург: Уральский юридический институт МВД РФ, 2016. 140c.

\section{Bibliography}

1. Gorsky A. A. Private charity and the activities of charitable organizations: some results of population surveys // Labor and social relations. 2020. No. 4. pp. 138149.

2. Moroz E. V. Strategies for including vulnerable groups of the population in society on the example of elderly people and disabled people of working age / / Sociology and law. 2018. No. 4 (42). pp. 6-16.

3. Elderly Russians: social well-being and lifestyle. Analytical review of VTsIOM (2019-2020). Moscow: VTsIOM Publishing House, 2021. 125c.

4. Tokareva E. A. Questions of terminology in the law of social security. Monograph. Yekaterinburg: Ural Law Institute of the Ministry of Internal Affairs of the Russian Federation, 2016. 140c. 